\title{
Cell-specific Alternative RNA Splicing of an FMRFamide Gene Transcript in the Brain
}

\author{
Susan E. Saunders, Elaine Kellett, Kerris Bright, Paul R. Benjamin, and Julian F. Burke \\ Sussex Neuroscience Research Centre, School of Biological Sciences, University of Sussex, Falmer, Brighton BN1 9QG, \\ United Kingdom
}

\begin{abstract}
Individual neurons synthesize different peptide neurotransmitters and neuromodulators. In general, specificity is achieved by transcriptional regulation of neuropeptide-encoding genes. In Lymnaea, the FMRFamide and GDP/ SDPFLRFamide neuropeptides are encoded by separate exons. Here we provide evidence that the two exons are part of the same gene and that in neurons expressing the gene the two exons are spliced onto a common upstream exon encoding a hydrophobic leader sequence. In addition, in situ hybridization data show that there is mutually exclusive cytoplasmic expression of each of the neuropeptide-encoding exons. Thus, differential neuropeptide synthesis is likely to be regulated by an alternative splicing mechanism. The cellular specificity of these splicing events is remarkable and suggests that cell-specific alternative splicing may be of major importance in establishing neuronal diversity in this system.
\end{abstract}

Neuropeptide genes often encode multiple peptides that are members of families of structurally related molecules. Not all members of a family are necessarily required for physiological function in particular cells, and so differential expression of peptides may occur. The mechanism of differential expression and whether it operates at the level of single neurons is difficult to determine in complex vertebrate nervous systems. The pond snail Lymnaea stagnalis, with its simple networks of identified neurons, offers an important system in which to address the problem of determining differential expression of members of families of structurally related neuropeptides at the level of the single neuron. A family of FMRFamide-like peptides occur in Lymnaea (Ebberink et al., 1987; Linacre et al., 1990; Saunders et al., 1991) that are involved in a number of behaviorally important neural circuits involved in the control of heart beat (Buckett et al., 1990b), egg laying (Brussaard et al., 1989), and respiration (Syed et al., 1990). Identified neurons within these circuits contain FMRFamide-related peptides, for example, the $\mathrm{E}_{\mathrm{he}}$ cells (Buckett et al., 1990b), heart excitatory motoneurons, and the Visceral White Interneuron (Benjamin et al., 1988).

The genomic sequences encoding the native Lymnaea tetrapeptide FMRFamide and the heptapeptides GDP/ SDPFLRFamide have previously been described (Linacre et al., 1990; Saunders et al., 1991). In each case, there is evidence to

\footnotetext{
Received May 6, 1991; revised Oct. 9, 1991; accepted Oct. 18, 1991.

This work was supported by SERC and MRC project grants and an SERC studentship to K.B. We thank Nicola Ford for preparation of the manuscript.

Correspondence should be addressed to Julian $F$. Burke at the above address.

Copyright (C) 1992 Society for Neuroscience $0270-6474 / 92 / 121033-07 \$ 05.00 / 0$
}

suggest that the two genomic sequences are exons and may make up part of a larger gene. First, one of two sequenced partial cDNAs homologous to the tetrapeptide-encoding sequence diverges from the genomic sequence at the extreme $5^{\prime}$ end at a good consensus splice site (Linacre et al., 1990), and second, the open reading frame encoding the heptapeptides GDP/ SDPFLRFamide lacks an inframe initiator methionine but is flanked by 3' and 5' consensus splice sites (Saunders et al., 1991). As the two classes of peptide are encoded by different exons, the question arises as to whether these two exons are part of the same gene and whether all the cells that express the gene(s) produce both classes of peptide, or whether differential processing of a common precursor RNA generates different mRNAs in different cell types. To investigate this, we have sequenced the DNA between the two exons and we have used PCR (Saiki et al., 1988) to amplify cDNA sequences $5^{\prime}$ to the tetra- and heptapeptide exons. In order to determine whether individual cells express both peptide-encoding exons, in situ hybridizations were performed on alternative sections with exon-specific probes and intron sequences between the two exons. The data suggest that both exons are spliced onto a common hydrophobic leader sequence and that the individual peptide-encoding exons are alternatively spliced in a cell-specific manner.

\section{Materials and Methods}

Materials. Restriction enzymes were purchased from Anglian Biotechnology or Boehringer Mannheim. Sequenase 2.0 was purchased from U.S. Biochemicals, and Taq DNA polymerase, from Perkin Elmer. Klenow for random priming, and nick translation kits were purchased from Amersham International. The $\alpha^{32} \mathrm{P}$-dCTP was purchased from ICN Radiochemicals; $\alpha^{35}$ S-dATP, Hybond-N, and autoradiographic LM-1 emulsion were purchased from Amersham. X-ray film was purchased from Kodak. Synthetic oligonucleotides were synthesized on an ABI $380 \mathrm{~A}$ synthesizer. The sequences of the $\lambda g t 10$ primers were based on the New England Biolabs forward and reverse primers.

Molecular procedures. Standard procedures were carried out as described by Sambrook et al. (1989).

PCR analysis of $\lambda c D N A S$. A plate lysate was made of a $\lambda g t 10 \mathrm{Lym}$ naea stagnalis CNS cDNA library (titer, $5 \times 10^{10}$ plaque-forming units $\mathrm{ml}^{-1}$ ); $500 \mu \mathrm{l}$ was phenol extracled and ethanol precipitated and resuspended in TE at $0.5 \mathrm{mg} / \mathrm{ml}$. Five hundred nanograms of DNA were resuspended in $100 \mu 1 \times 1 \mathrm{PCR}$ buffer $(50 \mathrm{~mm} \mathrm{KCl}, 0.2 \mathrm{~mm}$ dATP, dCIP, dGTP, dTTP, deoxynucleotide triphosphate (dNTP), $10 \mathrm{~mm}$ Tris, pH 8.4, $1.5 \mathrm{~mm} \mathrm{MgCl}_{2}$ ); 100 pmol of $\lambda$ gt 10 primer [forward $21 \mathrm{mer}$ 5'd(AGCAAGTTCAGCCTGGTTAAG) $3^{\prime}$ or reverse 5'd(CTTATGAGTATTTCTTCCAGGGTA) $\left.3^{\prime}\right]$ and $98 \mathrm{pmol}$ of FMRFamide primer 5'd(GTAGTGTCCAGAGCTCGGCCAAACC)3' complementary to the sequence encoding RFGRALDTT were then added. After denaturing for $10 \mathrm{~min}$ at $95^{\circ} \mathrm{C}$ and making up to $100 \mu \mathrm{l}$ with water, 1 $\mathrm{U}$ of Taq DNA polymerase (Perkin Elmer) was added and the sample cycled in a Techne Thermal cycler PCH-1 TCl under the following conditions: $95^{\circ} \mathrm{C}, 2 \mathrm{~min} ; 55^{\circ} \mathrm{C}, 2 \mathrm{~min}$; and $72^{\circ} \mathrm{C}, 2 \mathrm{~min}$. After 30 cycles, 
2.

genomic 5'... TTT CAC TCT GCA GTG ACC AAA CGC TTT TTG AGG TTT GGC CGA GCT CTG GAC ACT ACG...3' CDNA $5 ' \ldots$ TTT CAC TCT GCA GTG ACC AAA CGC TTT TTG AGG TTT GGC CGA GCT CTG GAC ACT ACG...3

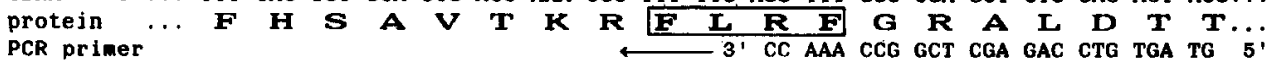

b.

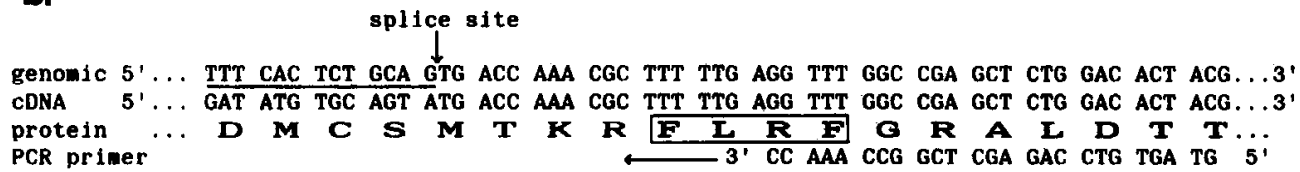

C.

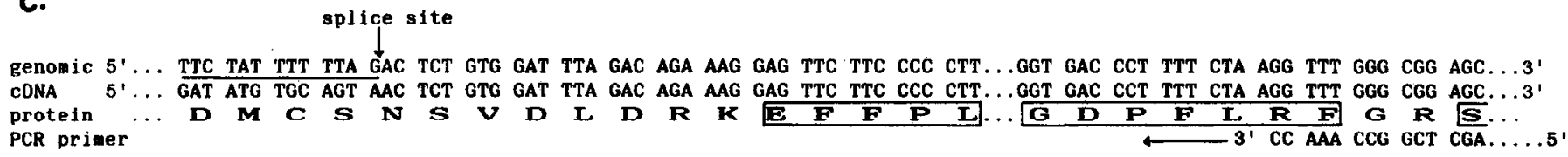

Figure 1. Comparison of Lymnaea genomic sequence and the corresponding cDNA sequences generated by PCR utilizing a $\lambda$ gt $10 \mathrm{cDNA}$ library as a template. The sequences obtained are divided into three classes $(a-c)$ corresponding to the genomic tetrapeptide-encoding sequence $(a)$, spliced tetrapeptide-coding sequence $(b)$, or spliced heptapeptide-coding sequences $(c)$. The region of homology to the PCR oligonucleotide is shown in each case. In all cases, the PCR sequences correspond precisely to the genomic sequences except where indicated (l), and at this point the sequences diverge. The site of divergence corresponds to consensus 3 ' splice sites in the genomic DNA (T/C)nN(C/T)AGl. The sequence of the first peptide in each precursoir class is shown, as is part of the common spliced hydrophobic leader sequence. The lengths [in base pairs (bp)] of the amplified

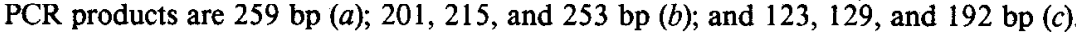

the reaction was chloroform extracted and kept at $-20^{\circ} \mathrm{C}$. Aliquots of the PCR products were withdrawn and ligated into pUC9 and transformed into $\mathrm{DH} 5 \alpha$, and white colonies were selected on agar plates containing ampicillin ( $100 \mu \mathrm{g} / \mathrm{ml}), X$-gal, and isopropyl- 1 -thio- $\beta$-D-galactopyranoside. White colonies were further screened by hybridization with FMRFamide genomic sequences and mixed oligomers to GDPF and SDPF.

DNA sequencing. Cloned PCR products were sequenced using templates prepared by a recently described miniprep method (Saunders and Burke, 1990). Reactions were carried out using $\alpha^{35}$ S-dATP and Sequenase 2.0 following manufacturers' instructions. Deoxyinosine triphosphate (dITP) was used where appropriate to resolve compressions. Genomic sequencing of 6.0 kilobases $(\mathrm{kb})$ of the Lymnaea genome was performed using nested deletions (Saunders et al., 1991), supplemented with M13 sequencing, and completed using synthetic primers and double-stranded templates.

In situ hybridization. Brains were dissected and frozen in Freon(FreezeJet, Agar Scientific). Fixation was performed in paraformaldehyde vapor $\left(2 \mathrm{hr}, 60^{\circ} \mathrm{C}\right)$. The brains were transferred to clear molten Paramat in an embedding mold and sectioned, and ribbons of embedded material were placed on slides. Slides were dewaxed in xylene $(30 \mathrm{~min})$, dehydrated in $100 \%$ methanol $(2 \mathrm{~min})$, immersed in $0.15 \%$ pepsin in $0.2 \mathrm{M} \mathrm{HCl}$ $\left(37^{\circ} \mathrm{C}, 10 \mathrm{~min}\right)$, rinsed in phosphate-buffered saline (PBS), fixed in $2 \%$ paraformaldehyde in PBS (5 min), rinsed in PBS, immersed in $1 \%$ hydroxylamine ammonium chloride (15 min), rinsed in PBS (10 min), upgraded in $100 \%$ ethanol, and air dried. Hybridization was performed in a moist chamber for $16 \mathrm{hr}$ at $37^{\circ} \mathrm{C}$ with ${ }^{35} \mathrm{~S}$-labeled nick translated cDNA probes (specific activities of probes ranged from $1 \times 10^{8}$ to $3 \times$ $10^{8} \mathrm{dpm} \mu \mathrm{g}^{-1}$, used at $10 \mathrm{ng}$ per slide) in a buffer containing $50 \%$ formamide, $3 \times$ saline-sodium citrate (SSC), $5 \times$ Denhardt's solution, $5 \%$ dextran sulfate, $10 \mathrm{~mm}$ dithiothreitol, and $0.5 \mathrm{mg} \mathrm{m}^{-1}$ transfer RNA. Sections were washed in $2 \times \mathrm{SSC}(30 \mathrm{~min}), 0.1 \times \mathrm{SSC}$ at $60^{\circ} \mathrm{C}$ $(10 \mathrm{~min}), 2 \times \mathrm{SSC}$ (10 min); upgraded in alcohol; dipped in Amersham LM-1 emulsion; exposed for $7 \mathrm{~d}$; and developed. Sections were counterstained with hematoxylin and eosin.

Genomic DNA isolation. Genomic DNA was extracted using a previously described procedure (Linacre et al., 1990).

\section{Results}

\section{PCR amplification of FMRFamide cDNAs}

To extend the two previously characterized partial cDNA sequences encoding the tetrapeptide precursor, an oligonucleotide was synthesized that was homologous to a unique region of the tetrapeptide precursor, $3^{\prime}$ to the potential splice site (Fig. 1). A plate lysate was made of a Lymnaea brain $\lambda g t 10$ cDNA library, total DNA was extracted, and FMRFamide cDNA inserts were amplified using the FMRFamide precursor primer, a $\lambda g t 10$ specific primer, and Taq DNA polymerase. After 30 rounds of amplification, the cDNA products were cloned into the SmaI site of pUC9 and transformed into DH $5 \alpha$, and colonies were selected for ampicillin resistance. From a single reaction, approximately 300 colonies were obtaincd. White colonies were picked, minipreps made, and the inserts double-strand sequenced using universal and reverse primers.

Two classes of cDNA product were identified and compared with the genomic sequences (Fig. $1 a, b$ ). One class (Fig. 1a), of which only a single member was identified, corresponded exactly in DNA sequence to the $5^{\prime}$ genomic region of the tetrapeptide exon and included the first encoded FLRFamide. The second class (three individual clones) of cDNAs (Fig. $1 b$ ) also encoded the first FLRFamide, but then the sequence diverged, before the presumptive initiating methionine at a $3^{\prime}$ splice consensus site in the genomic DNA.

\section{Screening of PCR library for GDPFLRFamide sequences}

The oligonucleotide designed to amplify FMRFamide sequences should also be capable of amplifying GDPFLRFamide sequences, as the $3^{\prime}$ nucleotides of oligonucleotide arc complementary to Arg-Phe-Gly, which is conserved between the two peptide precursors. The cloned PCR products were therefore rescreened by hybridization with genomic GDPFLRFamide sequence. Several strongly hybridizing colonies were found, and the plasmid DNAs were isolated and sequenced. Three of these sequences (Fig. 1c) were found to encode four copies of GDPFLRFamide, but diverged from the previously sequenced heptapeptide genomic sequence at a potential 3' splice site (Saunders et al., 1991). Surprisingly, the DNA sequence extending the heptapeptide sequence $5^{\prime}$ was identical to the $5^{\prime}$ 
A

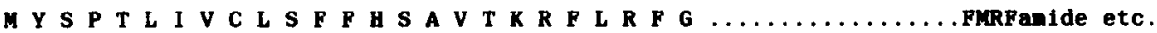

$\mathbf{B}$

1) I T T S I VA L L A C L S I K W L T C V M A D S I Y C D D P D M C S M T K R F L R F G .........FMFanide etc.

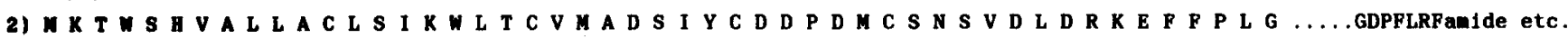

Figure 2. Translation of the hydrophobic sequence on the nonspliced tetrapeptide precursor $(A)$ and the spliced $(B)$ tetrapeptide $(I)$ and heptapeptide (2) precursors. Amino acid sequences are derived by translation of the PCR products (Fig. 1). The translated sequences extend the open reading frames toward the $\mathrm{N}$ terminus and end at the last methionine in the open reading frame. The common hydrophobic leader sequence that is spliced inframe onto the tetrapeptide and heptapeptide coding sequences is underlined.

sequence observed in the tetrapeptide spliced PCR products (Fig. $1 b$ ).

\section{Common spliced exon encodes a hydrophobic leader}

The splicing of the identical 5 ' sequence onto two different exons suggests that this common 5 ' exon may have an important physiological function. Translation of the spliced sequence shows that it is hydrophobic, it contains four cysteine residues, and it is spliced inframe to the open reading frames of both the heptaand tetrapeptide coding sequences (Fig. $2 B, 1$ and 2). Hydrophobic leader sequences are commonly found on neuropeptide precursors (Walter and Blobel, 1981). This common N-terminal hydrophobic sequence would provide a leader for the precursor protein encoded by the heptapeptide exon, and interestingly, it would replace the existing hydrophobic leader encoded by the $\mathrm{N}$-terminus of the precursor protein encoded by the nonspliced tetrapeptide transcript (Fig. 2A).

\section{Organization of the FMRFamide gene}

The splicing of identical sequences onto each of the two neuropeptide encoding exons is consistent with the two exons being part of the same gene. However, the hydrophobic leader could be encoded upstream of each exon, each with its own transcriptional promoter. If this were the case, the neuropeptide exons would have to be considered as separate genes.

To determine whether a spliced hydrophobic leader was encoded upstream of the heptapeptide exon and downstream of the tetrapeptide exon, the intervening DNA was sequenced. This region of DNA was isolated from the genomic $\lambda E M B L 3$ phage 4.5 previously described (Saunders et al., 1991), which was used as a source of DNA for sequencing of the heptapeptide exon; a map of the total genomic region sequenced is shown in Figure $3 A$. Manual and computer inspection of the genomic region sequenced, as well as hybridization of the genomic clone $\lambda 4.5$ with an oligonucleotide specific for the spliced hydrophobic leader, failed to reveal any homologous sequences (data not shown). Lymnaea genomic DNA was digested with a variety of restriction enzymes and then subjected to a Southern transfer and hybridized with the same oligonucleotide. By washing at high stringency $\left(6 \times \mathrm{SSC}\right.$ at $\left.65^{\circ} \mathrm{C}\right)$, a single band was observed in each track (Fig. 4). These data suggest that the spliced hydrophobic leader is elsewhere in the genome and is not located between the tetra- and heptapeptide exons.

A model based upon DNA sequencing and the PCR data is shown in Figure $3, A$ and $B$. In the genomic sequence (Fig. $3 A$ ), the exon encoding the common spliced hydrophobic leader sequence is $5^{\prime}$ to the tetrapeptide exon, which is in turn $5^{\prime}$ to the heptapeptide exon. The PCR data (Fig. $3 B$ ) suggest that both the tetra- and heptapeptide exons are spliced onto the common $5^{\prime}$ exon. To date, we have not been able to determine the distance between the tetrapeptide exon and the hydrophobic leader sequence. It is likely to be greater than $20 \mathrm{~kb}$ as several genomic $\lambda$-clones containing the tetrapeptide exon have been isolated and none contain the hydrophobic leader exon.

\section{In situ hybridization with neuropeptide-encoding exon and putative intron probes}

The model shown in Figure 3 suggests the possibility that alternative splicing between the neuropeptide exons could be used as a mechanism to regulate the cell-specific expression of the different exons and hence the production of different classes of neuropeptide. To test this in situ hybridization probes were generated (Fig. $3 \mathrm{C}$ ) and hybridized to mRNA in consecutive 7 $\mu \mathrm{m}$ brain sections. By hybridizing consecutive brain sections

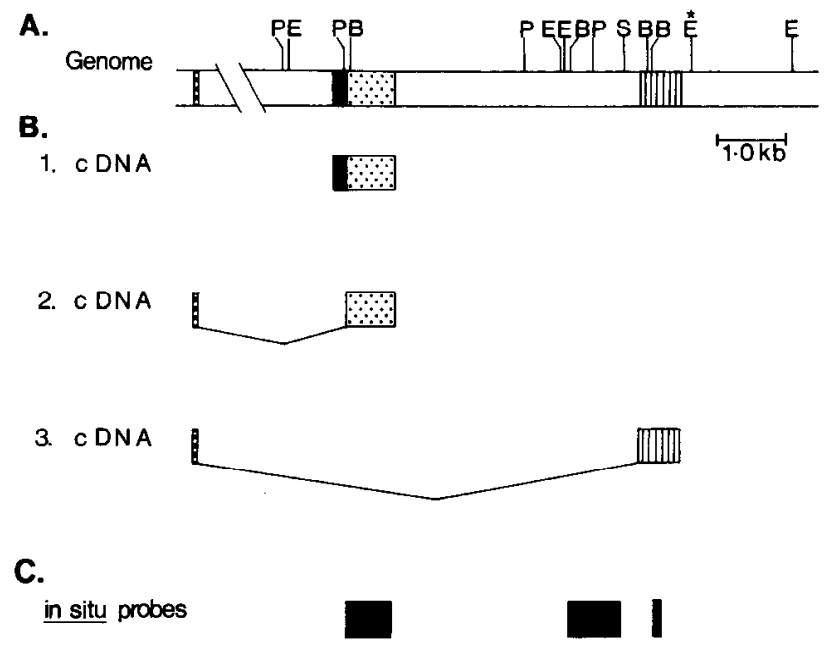

Figure 3. Organization of the FMRFamide locus in Lymnaea stagnalis. $A$, The genomic organization was determined by restriction endonuclease mapping and DNA sequencing of genomic DNA cloned into $\lambda E M B L 3$. The $6.0 \mathrm{~kb}$ region that has been sequenced is between the upstream $P s t 1$ site $(P)$ of the tetrapeptide exon and the $E c o$ RI site $(\stackrel{*}{E})$ downstream of the heptapeptide exon. $B$, The three classes of PCR products (Fig. 1) are aligned with the genomic sequences; exon sequences are shown as boxes and introns as lines where the dotted area represents the tetrapeptide exon with its hydrophobic leader sequence (solid area) and the vertical striped area represents the heptapeptide exon. The spliced hydrophobic leader is shown as the horizontal striped area. $C$, The organization of probes used for in situ hybridization is indicated. Restriction enzyme sites are indicated as $E, E c o \mathrm{RI}, B, B a m \mathrm{HI} ; S, S a l \mathrm{I}$; $P$, PstI. 


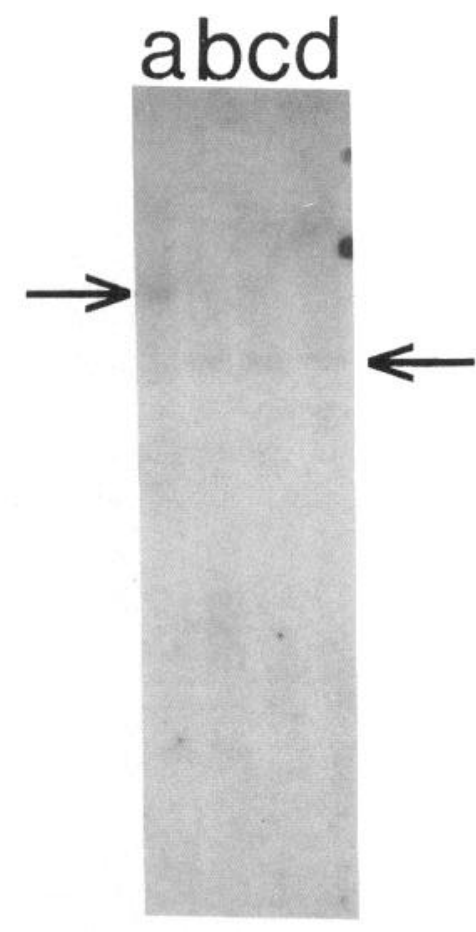

Figure 4. Southern transfer and hybridization of Lymnaea genomic DNA with a synthetic oligonucleotide labeled with $\gamma^{32}$ P-ATP 5'd(CATCAAATGGCTGACCTGTGTCATGGC) $3^{\prime}$ corresponding to part of the coding region of the spliced hydrophobic leader sequence shown in Figure 1. Lymnaea genomic DNA $(10 \mu \mathrm{g})$ was digested with EcoRI (a), EcoRI/HindIII (b), HindIII (c), and HindIII/DraI (d). The oligonucleotide was hybridized overnight at $65^{\circ} \mathrm{C}$ in $6 \times \mathrm{SSC}$ and washed at room temperature in $6 \times \mathrm{SSC}$ and then at increasing stringencies. An autoradiograph of the Southern blot after washing at $65^{\circ} \mathrm{C}$ in $6 \times \mathrm{SSC}$ is shown. The arrows indicate the predominantly hybridizing bands.

with two different DNA probes, hybridization to different RNA molecules in the same cell can be observed. This is possible as the average size of a cell body is more than $25 \mu \mathrm{m}$ in diameter.

The autoradiographs in Figure 5, $A$ and $B$, show neuronal cell bodies in consecutive sections in the visceral (Visc.) and right parietal (R.Pa.) ganglia hybridizing with tetrapeptide (Fig. 5A) and heptapeptide (Fig. $5 B$ ) exon-specific probes. It can be seen that expression of the two exons in the cytoplasm is mutually exclusive. A group of cells (Fig. 5A, arrow) in the visceral ganglion contains RNA in the cytoplasm that hybridizes very strongly with the tetrapeptide probe, whereas only two cells in the visceral ganglion (Fig. 5B, N4 and N5) and three large cells in the right parietal ganglion (Fig. $5 B, \mathrm{~N} 1, \mathrm{~N} 2$, and $\mathrm{N} 3$ ) hybridize with the heptapeptide probe.

The differential expression of cytoplasmic mRNA encoding tetrapeptides or heptapeptides could occur by differential transcription of the two exons; however, there do not appear to be any transcriptional promoter sequences between the tetrapeptide and heptapeptide exons (which have been sequenced), nor is differential transcription from separate promoters consistent with the PCR products in Figure $1, b$ and $c$. A more likely explanation, which is consistent with the model (Fig. 3), is that differential expression is a result of differential splicing from a single RNA transcript. It can be seen that neurons expressing the heptapeptide mRNA in their cytoplasm (Fig. 5B, N1 and $\mathrm{N} 2$ ) also contain tetrapeptide exon sequences in the nucleus (Fig. $5 A, \mathrm{~N} 1$ and $\mathrm{N} 2$ ). The converse is also the case. Though nuclear expression of heptapeptide RNA is weak in the visceral ganglion cell group heavily expressing tetrapeptide mRNA in its cytoplasm (Fig. 5A,B, arrow), obvious nuclear expression of heptapeptide RNA is observed when a probe of high specific activity is used and when cell bodies are observed under a higher magnification as shown in Figure 5, $C$ and $D$. Cells expressing tetrapeptide RNA in the cytoplasm (Fig. $5 C$, arrows) contain heptapeptide RNA restricted to the nucleus (Fig. $5 D$, arrows). These findings are again consistent with the model whereby cytoplasmic mRNA sequences are encoded by a common precursor RNA and transport of the two exons to the cytoplasm is the result of a cell-specific RNA splicing event.

Confirmation that the two exons are likely to be derived from the same primary transcript is shown in Figure $5 E$. The consecutive sections hybridized with either the probes specific for the tetrapeptide (Fig. $5 C$ ) or the heptapeptide (Fig. 5D) were also probed with a noncoding presumptive intron sequence (Fig. $3 C$ ) between the two coding exons. This shows (Fig. $5 E$, arrows) that cells expressing the tetrapeptide exon in their cytoplasm also contain the heptapeptide and intron sequences in their nuclei.

\section{Discussion}

Genes encoding FMRFamide-related peptides from Aplysia and Drosophila (Schaefer et al., 1985; Nambu et al., 1988; Schneider and Taghert, 1988) have been described previously. From the sequence of a number of cDNAs in Aplysia, it was suggested that splicing could occur although no firm model was proposed (Taussig and Scheller, 1986). In Drosophila, the gene encoding FMRFamide-related peptides clearly contains two exons (Schneider and Taghert, 1988), but the first exon appears to be noncoding and there is no evidence of any differential splicing occurring. The simplest interpretation of the PCR data described here from Lymnaea is that the predominant forms of tetrapeptide and heptapeptide transcripts are spliced onto a common exon encoding a hydrophobic leader sequence. It is clear from DNA sequencing that the hydrophobic leader sequence is not encoded between the hepta- and tetrapeptide exons. From the genomic Southern data and the fact that the nucleotide sequences of the hydrophobic leaders of the different PCR products are identical, it is likely that the hydrophobic leader is encoded as only a single copy, and therefore the tetra- and heptapeptide sequences are spliced onto the same sequence. However, we cannot rule out the possibility that the single bands observed in the Southern transfer may represent several identical copies of the leader grouped closely together, each with a transcriptional control region. In this case, tetra- and heptapeptide differential transcription could occur in different cells; however, to explain our in situ observations, cell-specific splicing of the neuropeptide-encoding exons would also have to occur. These data all suggest that the tetra- and heptapeptide exons make up part of a larger gene. Furthermore, from the sequence data there is no evidence of any initiating methionine or transcriptional regulatory sequences between the two neuropeptide-encoding exons. The single nonspliced tetrapeptide PCR product (Figs. $1 a, 3 B_{l}$ ) may represent a rare transcript from its own promoter that is produced in just one or a few cells, or is expressed at a low level in all cells producing FMRFamide. However, in the region sequenced upstream of the tetrapeptide exon there do not seem to be classic CAAT or TATA sequences encoded by the genomic DNA that are typical of many Lymnaea transcription promoters (Smit et al., 1988). Alternatively, this PCR prod- 


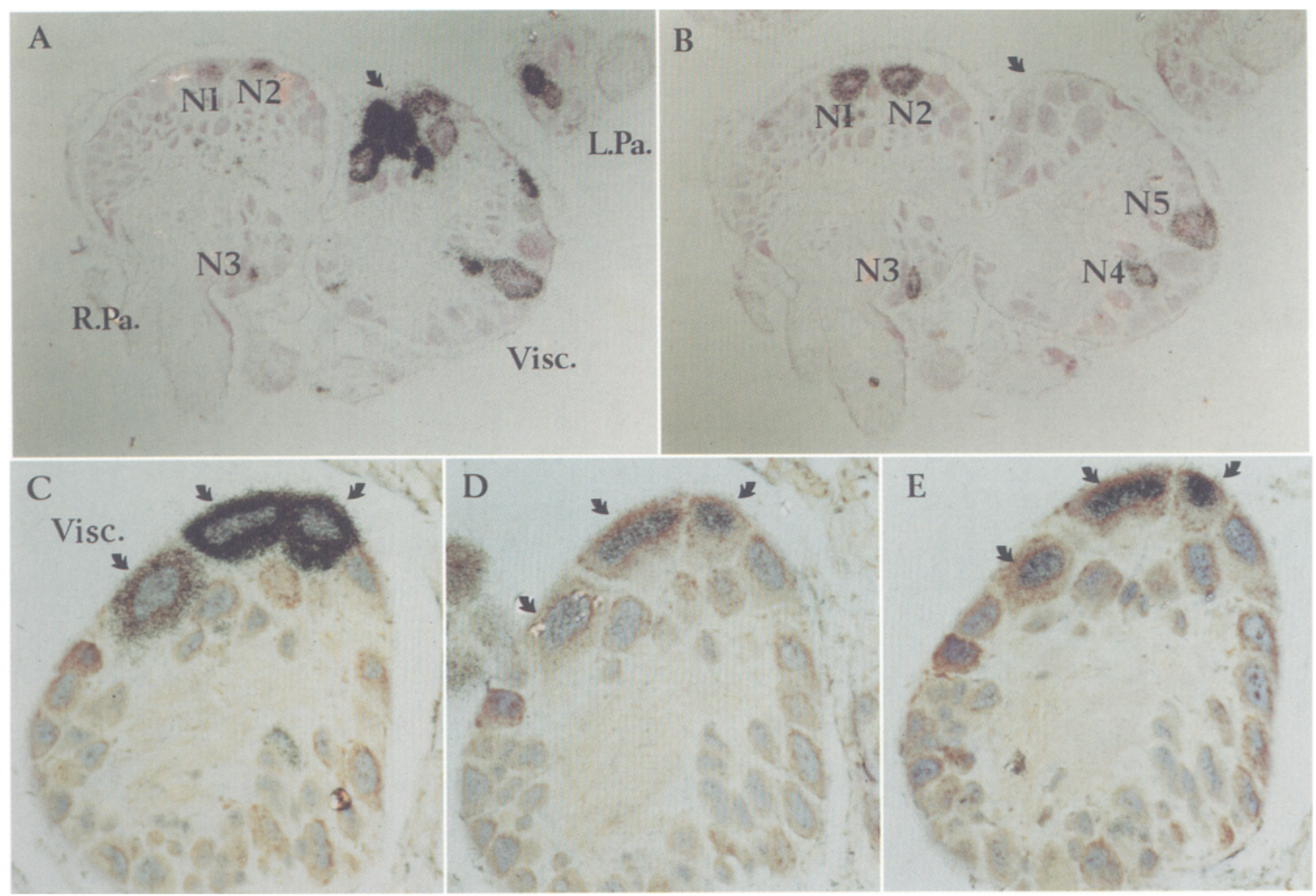

Figure 5. In situ analysis of the expression of the tetrapeptide exon- and heptapeptide exon-encoding transcripts in consecutive sections of the CNS of Lymnaea stagnalis. The probes used were as follows: $A$ and $C$, tetrapeptide probe, cDNA sequence (D3, described in Linacre et al., 1990) encoding nine copies of FMRFamide plus additional putative peptides; $B$ and $D$, heptapeptide probe, cDNA sequence encoding four tandem copies of GDPFLRFamide, corresponding to nucleotides 161-284 of Saunders et al. (1991). The fragment was cut out of pUC19, gel purified, and selfligated to create a larger template. $E$, Noncoding presumptive intron probe ( 695 base pairs) spanning the region between the $E c o$ RI and $S a l$ sites as shown in Figure 3, $A$ and $C$. The visceral (Visc.), right parietal (R.Pa.), and left parietal ( $L . P a$.) ganglia $(A$ and $B)$ are indicated. The group of neuronal cell bodies in the visceral ganglia expressing tetrapeptide mRNA is indicated (arrows), and cells expressing heptapeptide mRNA are labeled N1-N5.

uct may represent an incompletely spliced RNA that was cloned into the $\lambda g t 10 \mathrm{cDNA}$ library. Preliminary in situ data suggest that this nonspliced hydrophobic sequence is maintained in the nucleus and probably never reaches the cytoplasm.

The observation that the tetrapeptide exon is spliced onto a hydrophobic leader is surprising since translation of the genomic tetrapeptide open reading frame appears to encode an apparently normal hydrophobic leader. However, this nonspliced leader is relatively short, containing only six hydrophobic amino acids, and is the least hydrophobic of over 300 hydrophobic leaders surveyed (Linacre et al., 1990). The spliced leader is more hydrophobic, containing 15 hydrophobic amino acids and a likely cleavage site (von Heijne, 1986) between tryptophan and lysine just adjacent to the cleavage site for the first predicted peptide, FLRFamide. The possibility exists that both hydrophobic leader sequences are used, maybe in different cells. If this is the case, they could function to target the precursor protein to specific cellular locations for processing or releasing. This can be tested by further in situ hybridization experiments and specific antisera against each leader sequence.

Of particular interest is that the spliced hydrophobic leader sequence shares strong sequence conservation with one of the spliced Aplysia tetrapeptide-coding sequences (Taussig and
Scheller, 1986) (Fig. 6). The conservation of this splicing event between the two species indicates that it is likely to be of some physiological importance, not least in targeting these precursors to their specific locations for processing. It remains to be determined whether the same hydrophobic sequence is spliced onto a heptapeptide-coding exon in Aplysia, though we think this is likely.

In vertebrate systems, several examples of tissue-specific alternatively spliced transcripts have been described (reviewed in Smith et al., 1989). Bovine preprotachykinin (PPT) is spliced in a tissue-specific manner (Nawa et al., 1984). The $\beta$-PPT mRNA containing exons 1-7 encoding both substance $\mathrm{P}$ and substance $\mathrm{K}$ is expressed predominantly in the thyroid and intestine, whereas the $\alpha$-PPT mRNA lacking exon 6 and therefore only encoding substance $\mathrm{P}$ is expressed in the nervous system. Similarly, the differential production of calcitonin/CRP and calcitonin gene-related peptide in the thyroid and nervous system, respectively, of humans is regulated by alternative splicing (Rosenfeld et al., 1983).

The in situ hybridization data described here are consistent with the two peptide-coding exons being part of a common transcript that is then differentially spliced in different cells, in a defined cell-specific manner. Different splicing of the 


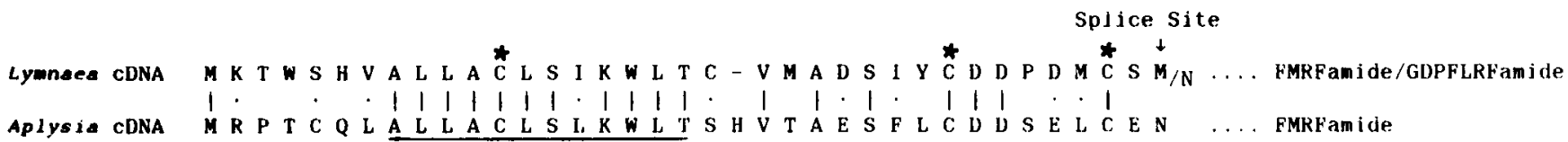

Figure 6. Comparison of the deduced amino acid sequences of the Lymnaea spliced hydrophobic leader sequence and the signal sequence of the spliced Aplysia FMRFamide-5 cDNA (Taussig and Scheller, 1986). Out of a total of 36 amino acids in Lymnaea and 37 in Aplysia [after the predicted $3^{\prime}$ splice site $(\downarrow)$ ], 19 are conserved $(\mid)$, including 3 cysteines $\left(^{*}\right)$. In addition, nine amino acids represent conservative substitutions $(\cdot)$. The most highly conscrved region of 12 amino acids, which forms part of the most hydrophobic region in the leader sequence, is underlined.

FMRFamide gene differs from the vertebrate systems in that expression is cell specific rather than just tissue specific. In another invertebrate, Aplysia, the R15 neuropeptide precursor is encoded by two different mRNAs that can be generated by a mechanism of alternative splicing (Buck et al., 1987). The two different $m R N A s$ differ in a single region whereby a 6 nucleotide sequence present in one mRNA (R15-1) is replaced by a different 48 nucleotide sequence in the alternative mRNA (R15-2) specific to the R15 neuron. The R15-2 mRNA encodes three peptides, R15 $\alpha, R 15 \beta$, and R15 $\gamma$. The physiological function of this system has recently been established (Alevizos et al., 1991a-c). Activity in the R15 neuron increases the frequency of bursting in R25/L25, which triggers respiratory pumping; this is modulated by the R $15 \alpha 1$ peptide derived from a protein precursor that is created by the cell-specific splicing in R 15 . Excitation of L7 is also mediated by this peptide, as are peristaltic movements in the hermaphroditic duct of Aplysia.

The physiological role of the alternative splicing observed here has yet to be established, although preliminary data (not shown) suggest that the E-group cells containing the heart motoneurons use the tctrapcptide exon specifically. This is consistent with the physiology of the heart in Lymnaea (Buckett et al., 1990a,b; Brezden et al., 1991). A detailed study of this and other systems is in progress.

The reproducibility of cell-specific alternative splicing of the tetra- and heptapeptide exons from one animal to another is extremely high. In over 250 individual cells expressing the tetrapeptide exon and approximately 50 cells expressing the heptapeptide exon, not a single case of coexpression in the cytoplasm has yet been observed. No differences between individual animals collected over a 2 year period have been observed. This high level of consistency most likely represents an extreme form of cell-specific differential splicing, although at this stage we cannot say whether splicing is responsible for differential expression of the two exons in every cell in the Lymnaea brain. The regulation of alternate splicing is likely to be due to a combination of factors such as the DNA sequence in the intron between the-two neuropeptide-encoding exons and differential cellular expression of small nuclear RNAs and/or proteins that regulate the splicing event (Guthrie and Patterson, 1988).

\section{References}

Alevizos A, Weiss KR, Koester J (1991a) Synaptic actions of identified peptidergic neuron R15 in Aplysia. I. Activation of respiratory pumping. J Neurosci 11:1263-1274.

Alevizos A, Weiss KR, Koester J (1991b) Synaptic actions of identified peptidergic neuron R15 in Aplysia. II. Contraction of pleuroabdominal connectives mediated by motoneuron L7. J Neurosci 11:12751281.

Alevizos A, Weiss KR, Koester J (1991c) Synaptic actions of identified peptidergic neuron R15 in Aplysia. III. Activation of the large hermaphroditic duct. J Neurosci 11:1282-1290.

Benjamin PR, Buckett KJ, Peters M (1988) Neurones containing
FMRFamide-like peptides in the model invertebrate system Lymnaea. Symp Biol Hung 3:247-259.

Brezden B, Benjamin PR, Gardner DR (1991) FMRFamide activates a divalent cation-conducting channel in heart muscle cells of the snail Lymnaea stagnalis. $\mathbf{J}$ Physiol (Lond), in press.

Brussaard AB, Kits KS, Ter Maat A (1989) One receptor type mediates two independent effects of FMRFamide on neurosecretory cells of Lymnaea. Peptides 10:289-297.

Buck LB, Bigelow JM, Axel R (1987) Alternative splicing in individual Aplysia neurons generates neuropeptide diversity. Cell 51:127-133.

Buckett KJ, Dockray GJ, Osborne NN, Benjamin PR (1990a) Pharmacology of the myogenic heart of the pond snail Lymnaea stagnalis. J Neurophysiol 63:1413-1425.

Buckett KJ, Peters M, Dockray GJ, van Minnen J, Benjamin PR (1990b) Regulation of heartbeat in Lymnaea by motoneurons containing FMRFamide-like peptides. J Neurophysiol 63:1426-1435.

Ebberink RHM, Price DA, Van Loenhout H, Doble KD, Riehm JP, Geraerts WPM, Greenberg MJ (1987) The brain of Lymnaea contains a family of FMRFamide-like peptides. Peptides 8:515-522.

Guthrie C, Patterson B (1988) Spliceosomal snRNAs. Annu Rev Genet 22:387-419.

Linacre A, Kellett E, Saunders SE, Bright K, Benjamin PR, Burke JF (1990) Cardioactive neuropeptide Phe-Met-Arg-Phe-NH (FMRFamide) and novel related peptides are encoded in multiple copies by a single gene in the snail Lymnaea stagnalis. J Neurosci 10:412-419.

Nambu JR, Murphy-Erdosh C, Andrews PC, Gottfried J, Feistner CJ, Scheller RH (1988) Isolation and characterization of a Drosophila neuropeptide. Neuron 1:55-61.

Nawa H, Kotani H, Nakanishi S (1984) Tissue-specific generation of two preprotachykinin mRNAs from one gene by alternative RNA splicing. Nature 312:729-734.

Padgett RA, Grabowski PJ, Konarska MM, Seiler S, Sharp PA (1986) Splicing of messenger RNA precursors. Annu Rev Biochem 55:11191150.

Rosenfeld MG, Mermod JJ, Amara SG, Swanson LW, Sawchenko PE, Rivier J, Vale WW, Evans RM (1983) Production of a novel neuropeptide encoded by the calcitonin gene via tissue-specific RNA processing. Nature 304:129-135.

Saiki RK, Gelfand DM, Stoffel S, Higuchi RH, Horn GT, Mullis KB, Erlich HA (1988) Primer-directed enzymatic amplification of DNA with a thermostable DNA polymerase. Science 223:487-491.

Sambrook J, Fritsch EF, Maniatis T (1989) Molecular cloning: a laboratory manual, $2 \mathrm{~d}$ ed. Cold Spring Harbor, NY: Cold Spring Harbor Laboratory.

Saunders SE, Burke JF (1990) Rapid isolation of miniprep DNA for double strand sequencing. Nucleic Acids Res 18:4948.

Saunders SE, Bright K, Kellett E, Benjamin PR, Burke JF (1991) Neuropeptides GDPFLRFamide and SDPFLRFamide are encoded by an exon $3^{\prime}$ to FMRFamide in the snail Lymnaea stagnalis. J Neurosci 11:740-745.

Schaefer M, Picciotto MR, Kreiner T, Kaldany R-R, Taussig R, Scheller RH (1985) Aplysia neurons express a gene encoding multiple FMRFamide neuropeptides. Cell 41:457-467.

Schneider LE, Taghert PH (1988) Isolation and characterization of a Drosophila gene that encodes multiple neuropeptides related to PheMet-Arg-Phe- $\mathrm{NH}_{2}$ (FMRFamide). Proc Natl Acad Sci USA 85:19931997.

Smit AB, Vreugdenhil E, Ebberink RHM, Geraerts WPM, Klootwijk J, Joose J (1988) Growth-controlling molluscan neurons produce the precursor of an insulin-related peptide. Nature 331:535-538.

Smith CWJ, Pattern JK, Nadal-Ginard B (1989) Alternative splicing in the control of gene expression. Annu Rev Genet 23:527-577. 
Syed NI, Bulloch GM, Lukowiak K (1990) In vitro reconstruction of the respiratory central pattern generator of the mollusc Lymnaea. Science 250:282-285.

Taussig R, Scheller RH (1986) The Aplysia FMRFamide gene encodes sequences related to mammalian brain peptides. DNA $5: 453-461$.

Von Heijne G (1986) A new method for predicting signal sequence cleavage sites. Nucleic Acids Res 14:4683-4690.
Walter P, Blobel G (1981) Translocation of proteins across the endoplasmic reticulum. II. Signal recognition protein (SRP) mediates the selective binding to microsomal membranes of in vitro-assembled polysomes synthesising secretory protein. J Cell Biol 91:551-556. 